Article

\title{
Monitoring Traditional Rural Landscapes. The Case of Italy
}

\author{
Mauro Agnoletti, Francesca Emanueli, Federica Corrieri ${ }^{\circledR}$, Martina Venturi and \\ Antonio Santoro *iD \\ Department of Agriculture, Food, Environment and Forestry (DAGRI), University of Florence, Via San \\ Bonaventura 13, 50145 Florence, Italy; mauro.agnoletti@unifi.it (M.A.); francesca.emanueli@unifi.it (F.E.); \\ federica.corrieri@unifi.it (F.C.); martina.venturi@unifi.it (M.V.) \\ * Correspondence: antonio.santoro@unifi.it
}

Received: 19 September 2019; Accepted: 28 October 2019; Published: 2 November 2019

check for updates

\begin{abstract}
The importance of rural landscapes is recognized at both the international and national level. The Food and Agriculture Organization (FAO) has established a program called Globally Important Agricultural Heritage Systems (GIAHS) and agricultural landscapes are also listed in the UNESCO World Heritage List. The World Bank and the Convention on Biological Diversity also have departments working on this topic, while landscape has been included in the Common Agricultural Policy of the European Union 2020-2027. One of the most important tools for landscape management, conservation and valorization is the development of a monitoring system, suited to control not only dynamics, but also the effectiveness of the policies affecting rural landscape. A research project of the Italian Ministry of Agricultural, Food and Forestry Policies has identified 123 areas scattered in the entire Italian territory, with an average size of 1300 ha, in order to establish a national monitoring system for traditional rural landscapes. As a result of this national survey, the Ministry decided to establish the National Register of Historical Rural Landscapes, that is also the Italian list for potential application to GIAHS. These landscapes are characterized by a long history, presence of traditional practices, typical foods, complex landscape mosaics and high biocultural diversity. Detailed land use maps have been produced for each area, and among other data, the average number of land use types (19.6 ha) and the average patch size (2.7 ha) detected, confirm the fine grain of these landscapes characterized by high complexity and diversity of the landscape structure. A second survey was carried out five years later, in order to create a national monitoring system based on fixed study areas. The paper shows that in the last five years no major changes occurred, and even in the 33 areas where transformations are considered significant (i.e., $>5 \%$ of the surface of the area), the characteristic features of the historical landscape are still well preserved. This confirms the resilience of these systems despite climatic and socioeconomic pressures.
\end{abstract}

Keywords: landscape monitoring; agriculture; forests; GIAHS; historical landscape; planning; rural policies; environmental policies

\section{Introduction}

The rural landscape is one of the most historically representative expressions of cultural identity, due to the importance of rural civilizations in history. Nowadays, high quality landscapes, especially those characterized by the conservation of values related to traditional practices, typical foods, and biocultural diversity [1] represent a fundamental part of rural development strategies and environmental conservation.

The increasing importance of these landscapes is also recognized at the international level. The Food and Agriculture Organization (FAO) of the United Nations has established a program called 
Globally Important Agricultural Heritage Systems (GIAHS) for the valorization of land use systems and landscapes, which are rich in biological diversity evolving from the co-adaptation of a rural community with its environment, including 57 sites across the world. Rural landscapes are also listed in the UNESCO World Heritage List (WHL) among cultural landscapes.

In Italy, the main institutional initiative regarding the rural landscape is the establishment of the National Observatory for Rural Landscape, Agricultural Practices and Traditional Knowledge in 2012 by the Ministry of Food, Agricultural and Forest Policies. This decision was the consequence of the results of a research project called National Catalogue of historical rural landscapes aimed at identifying and studying the most important rural landscapes at the national level. Italy still retains a unique heritage of historical rural landscapes, shaped during the centuries that are still important for their productive role, as well as for the identity of the local communities, that still keep an active role for the society and the rural economy [2,3]. Historical rural landscapes are indissolubly tied to the maintenance of traditional practices that farmers and shepherds have used for centuries [4]. These are ingenious and diversified techniques that have contributed to the creation and preservation of European historical, cultural, and natural heritage [5,6].

They represent an added value to the local products and an important economic resource, in particular for the marginal areas where traditional products and tourism can constitute the main resources for improving the quality of life of the local communities. These landscapes are also important for the preservation of biocultural diversity [7], as they have a great biological and cultural value [8-11]. Complex landscape mosaics that often characterize these landscapes maintain different habitats that are used by different animal and plant species [12]. Taking into account all these different aspects related to historical rural landscapes, it is clear that rural landscapes have an important multifunctional role, not only related to productive and economic functions, but also cultural and environmental ones $[13,14]$. As a consequence of the rapid socio-economic changes that have involved European countries in the last century, most of the traditional landscapes are facing significant changes and threats [15]. The industrialization and specialization of agricultural productions which started after WWII, and until 20 years ago seemed to be the only way to keep agricultural productions profitable, have proved to be ineffective, since our agricultural products cannot rely on low prices.

In Italy, 4881 typical products are listed by the Ministry of Food, Agricultural and Forest Policies, and agritourism business has grown by $60 \%$ in the last 10 years. In this context, landscape quality is a fundamental element for the development of rural areas [3], also considering that only $23 \%$ of the country shows a positive role of industrial agriculture models, while the rest of the rural territory is witnessing a failure of models based on high yield and low labor cost, contributing to the abandonment of rural territory. Consumers are looking more and more for typical products, products of high quality strictly associated with territories and the quality of the landscape, so that consuming a specific product is reminiscent of a specific place and landscape [6,13,16-20].

Rural landscapes in Europe had almost preserved their characteristics unchanged until WWII; they always adapted to socio-economic changes, but without losing features of their identity [21-23]. After this period traditional landscapes faced big changes, some of them disappeared, but many of them remain fundamental for rural communities, and it is therefore necessary to monitor and evaluate the transformations that involve our rural territories. In Italy, almost 10,000,000 ha of agricultural land has been abandoned ( $30 \%$ of the total extension of the country) in the last 100 years, which means that more than the half of the territory once cultivated has been lost. The loss of cultivated land favored the expansion of woods from $10 \%$ in 1920 to currently $34 \%$; this continues to grow at a rate of about 75,000 ha per year. This process has changed the landscape of whole regions, especially hills and mountains, reducing the variety of the landscape mosaic and replacing it by extended homogeneous forest covers. In agricultural areas, mostly on the plains, industrialization has also reduced the diversity of the mosaic, increasing the size of fields and reducing the number of patches [2]. These huge changes, entirely due to socioeconomic processes, has negatively affected landscape quality, food production, biocultural diversity, agrobiodiversity, and hydrogeological risk. Despite the repeated warning of 
possible deforestation processes due to climate change, if the present trends continue, at the end of the century we will have large urban areas in the plains surrounded by only $3-4$ millions of hectares of farmed land, while mountains and hills ( $74 \%$ of the country) will be covered by forests, as described in the first report on the state of rural landscapes produced by the Italian Ministry of Food, Agricultural and Forest Policies in 2018 (https://www.reterurale.it/flex/cm/pages/ServeBLOB.php/L/IT/IDPagina/18583). These trends also suggest a modification of the Italian Forest Law, which generally protects all forested areas, allowing for the restoration of abandoned cultivated land removing secondary forests.

Considering the above, the Ministry of Food, Agricultural and Forest Policies decided to establish a monitoring system, to assess the level of integrity as well as the main vulnerabilities, of valuable rural landscapes, especially those maintaining historical values and traditional practices. The research has been further developed according to a project of the Italian Agency for Development Cooperation based on GIAHS to develop features suited for this FAO program (www.agriculturalheritage.com). Monitoring the rural landscapes is crucial in order to make provisions about future evolution and to properly address landscape and territorial planning. The use of comparative analysis, such as the one presented in this study, is widespread in different countries in Europe and in the rest of the world [24-31], but monitoring systems for landscape changes in other countries are different for purposes and methodologies, and not specifically designed for historical landscapes as the one presented in this paper. Comparative analysis obtains much information about the quality of a given landscape and the main causes of vulnerability. The use of comparative analysis is therefore useful for evaluating the effectiveness of landscape and territorial policies and planning tools aimed at preserving the characteristic features of historical rural landscapes.

\section{Materials and Methods}

The research project carried out in the years 2009-2010 to identify historical rural landscapes involved 14 Italian universities and some international research institutions (UNESCO World Heritage Centre, Council of Europe, IUFRO, UNISCAPE) and it was coordinated by the Laboratory for Landscape and Cultural Heritage of the School of Agriculture of the University of Florence (Italy). The research identified 123 areas, distributed in all the Italian regions (Figure 1), characterized by the presence of historical landscapes [2]. The aim of the research was not to carry out a complete survey of Italian historical landscapes, but to give an idea of their wealth and variety. The size of the 123 areas vary from 218 ha to 5750 ha. All these landscapes are characterized by forms of cultivation that date back to ancient times, most of them to the Middle Ages, but some of them date as far back as Roman or even pre-Roman times. The aim of the project was not to select all the historical landscapes of Italy, but to provide examples of the variety and richness of rural landscapes in Italy that are still important for the cultural identity and economy of the local communities. The data concerning tourism in Italy show the preference for cultural landscapes, especially spending holidays in rural houses, as well as a great interest in traditional foods [32]. The importance of landscape is also confirmed by the fact that the National Statistical Agency included rural landscape quality among the indicators of wellbeing of the population [33], indicating abandonment and reforestation as a negative process, as well as the degree of conservation of historical rural landscapes. The 123 landscapes surveyed have been described taking into account their historical value, typical products, overall level of integrity, and critical issues that threaten their maintenance. Their description is accompanied by essays that illustrate the collected data, trends, and characteristics of Italian rural landscapes, bearing in mind historical, environmental, and economic issues. 


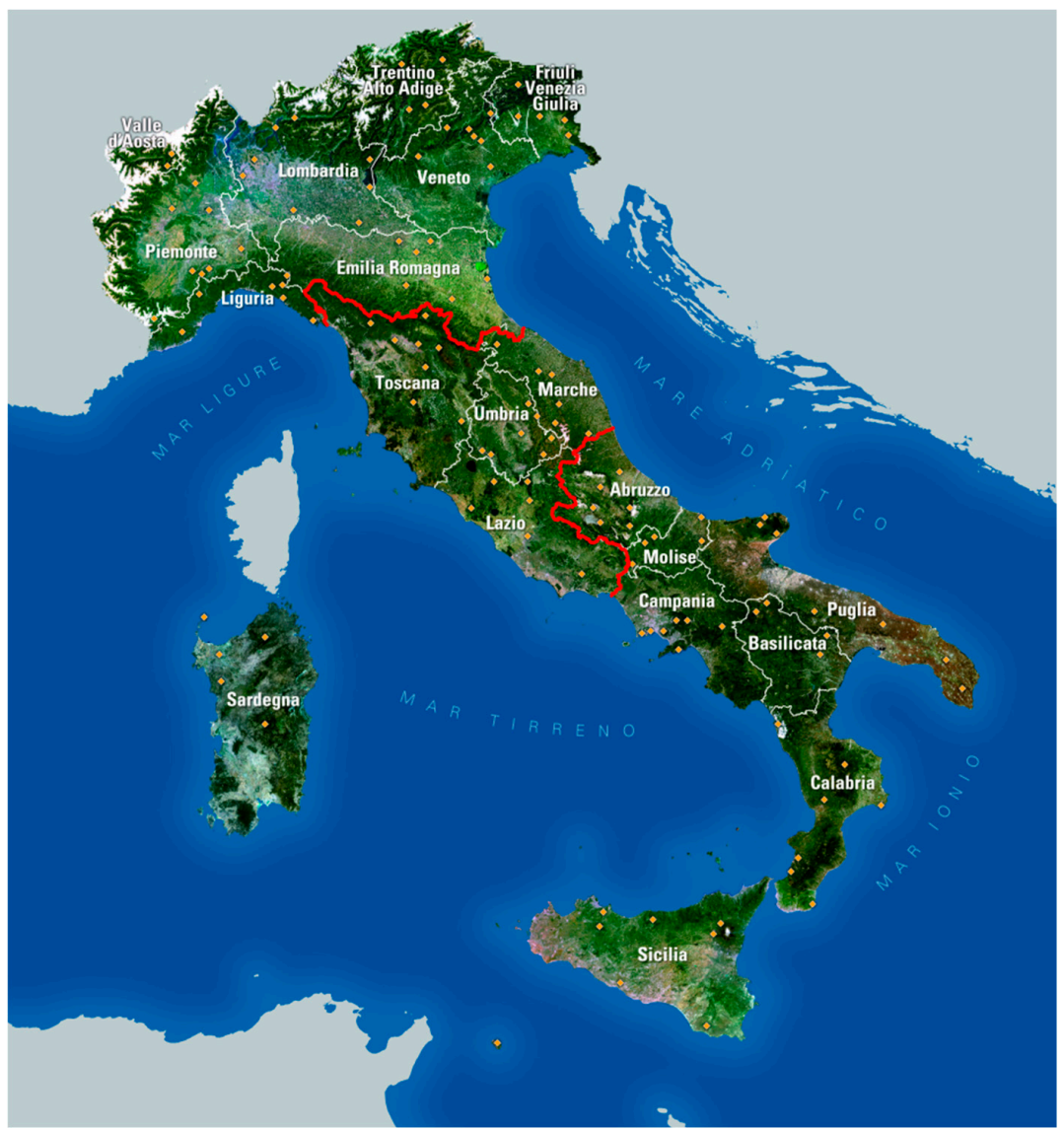

Figure 1. The localization of the 123 areas (yellow symbols) selected for the National Catalogue of Historical Rural Landscapes and the division of Italy in the north, center, and south (islands are officially part of the south).

After the first phase of the project, based on identifying and describing the areas, the second phase was focused on analyzing these areas through photointerpretation using Quantum GIS software (QGIS) of high-resolution orthophotos $(50 \mathrm{~cm}$ ) of the years 2007-2010 (depending on the availability of the images). The total surface of the selected historical landscape is equal to 167,591 ha. The 123 areas were photo interpreted applying a highly detailed legend with a minimum mappable unit equal to $500 \mathrm{~m}^{2}$. Dealing with historical landscapes, it is necessary to apply a methodology capable of describing landscapes often characterized by high complexity and by many land uses. In fact, current land use maps and dataset at the national or even European level, such as the Corine Land Cover (CLC) were not developed to investigate cultural historical landscapes, since they have a minimum mappable unit equal to 25 ha and a much too simplified land use legend. Moreover, they do not provide information about the presence of important historical rural features, such as dry-stone walls and terraces. In Italy, certain regions have updated CLC maps, creating maps with higher detail; but since each region has applied its own standards, it is not possible to use these maps and data for a national research survey.

The analysis of the 123 areas has not only focused on land uses, but also the structure of the landscape mosaic and other features which were taken into account, through the application of the following indexes:

- Number of land uses

- Average patch surface

- Edge density

- Level of integrity of the historical landscape

- Percentage of protected areas and areas subjected by landscape restrictions 
In addition to these indexes, data have also been analyzed according to the altitude (mountains, hills, plains), the geographical localization (north, center, south, and islands), and to the main historical landscape typology (agriculture, forest, pastures, mixed). Regarding the altitude, the official subdivision used in Italy was used: plains 0-200 m a.s.l. (meters above sea level), hills 200-600 $\mathrm{m}$ a.s.l., mountains $>600 \mathrm{~m}$ a.s.l. The geographical localization follows the official Italian subdivision: north (Emilia-Romagna, Friuli-Venezia Giulia, Liguria, Lombardia, Piemonte, Trentino Alto Adige, Valle d'Aosta, Veneto), center (Lazio, Marche, Toscana, Umbria), south and islands (Abruzzo, Basilicata, Calabria, Campania, Molise, Puglia, Sardegna, Sicilia).

The edge density (ED) is calculated as the ratio between the sum of the lengths of the edge of the patches $(\mathrm{E})$ divided by the total patch area $(\mathrm{A})$, multiplied by 10,000 (to convert to ha): $\mathrm{ED}=\mathrm{E} / \mathrm{A} \times 10,000$.

$\mathrm{ED}$ evaluates the level of fragmentation of a certain landscape. The higher the value of the index, the higher the fragmentation and the complexity of the landscape, while in the case of lower values, the landscape basically consists of a few, big regular patches.

The level of integrity of the historical landscape is calculated as the percentage of the surface actually occupied by traditional land uses on the total area (Table 1). This is only an estimate, susceptible to a good margin of error, because true integrity can only be established by comparing the landscape of the same area in two different periods. However, the estimate that has been made through this methodology, provides an important picture of the real situation. The percentage value is then inserted into a class system, from I to VI, with Class I landscapes characterized by a very low level of integrity of the historical landscape, and Class VI landscapes with very high integrity (Figure 2). In addition to the estimation of the overall level of integrity of the historical landscape, this index assesses the main causes of vulnerability.

Table 1. Tab of the six classes of the level of integrity of the historical landscapes and the corresponding percentage intervals. In the results section, the values are expressed as Arabic numbers (from 1 to 4 ), as they are calculated as average values.

\begin{tabular}{cc}
\hline Percentage of Integrity & Class of Integrity \\
\hline $0-19 \%$ & I \\
$20-34 \%$ & II \\
$35-49 \%$ & III \\
$50-64 \%$ & IV \\
$65-79 \%$ & V \\
$80-100 \%$ & VI \\
\hline
\end{tabular}

One of the characteristics that has been investigated is the presence of protected areas or areas affected by landscape restrictions. These types of protections come from European or national laws, and are intended for environmental protection, but are applied in places characterized by the presence of historical agricultural activities. Thus, it is important to evaluate the effects of these forms of protection on historical landscape conservation.

Since some years have passed from the identification and assessment of the 123 areas, monitoring was carried out to evaluate any changes that occurred to the historical rural landscapes at the national level. Orthophotos and satellite images of the years 2015-2018 were analyzed through GIS software, and the results were compared to the initial situation.

The monitoring is based on a methodology called the historical and cultural evaluation approach (HCEA), which evaluates landscape changes taking into consideration the landscape features that define the cultural identity of a specific territory. This methodology, based on comparing the landscape of the past with the current one, is particularly effective for measuring the main changes and trends in historical cultural landscapes, as well as for verifying the level of integrity of the traditional landscape and the main vulnerabilities. It was developed during research on the monitoring system for the landscape of Tuscany $[16,34]$ and nowadays it is the official methodology of the National Observatory of Rural Landscape established in 2012 by the Italian Ministry of Food, Agricultural and Forest Policies. 
For defining the degree of conservation and integrity of a historical landscape, it is necessary, in fact, to compare the maps of land use of two different periods, in order to identify which are the main changes that have involved the landscape. Using GIS software, the maps are overlaid, with the consequent creation of a new layer, consisting of a new map and a new database. In the new database, each polygon will report the land use of the past and current land use. Depending on the change, a particular evolutionary dynamic will then be associated with the polygon, which will constitute a new attribute within the table. According to the HCEA methodology, the changes can be summarized in seven dynamics:

- Unchanged: the main type of land use remains constant on the same polygon over time, or when there is a change, but between similar land uses, as occurs for examples between two types of woods or between a specialized vineyard and an olive grove.

- Anthropization: replacement of natural or seminatural land uses with urban areas, infrastructures, or buildings.

- Intensification: the passage from low-consumption land uses (in terms of biomass removal, mechanization, fertilizer, and crop protection products), such as meadows, pastures or traditional crops, to land uses characterized by high specialization and by a high need of energy supplies, such as monocultures.

- Extensification: the opposite of intensification, which is only rarely linked to a return to traditional land uses, but more often occurs in the presence of the phenomenon of abandonment of agricultural land or pastures.

- Forestation: natural process that occurs by secondary succession, in which trees or shrubs occupy patches once used as pastures or cultivations.

- Conifer afforestation: process that is directly related to human intervention, such as reforestation with conifers. Forestation and conifer expansion are two similar processes, but they are kept separate because they have different origins, although they always identify the expansion of the forest on former agricultural areas or pastures. Forestation is a natural process, which occurs by secondary succession, while conifer expansion indicates the planting of conifer trees by men, an activity that has shaped the Italian landscape especially during the 1960s.

- Deforestation: removal of woodlands or shrublands for obtaining pasture or agricultural lands.

According to these seven dynamics, each polygon is classified, and a cartography of land use transformations is created through GIS, which localizes these dynamics within the considered area, and therefore evaluates the overall landscape integrity and the main causes of vulnerability.

\section{Results and Discussion of the First Phase}

\subsection{Number of Land Uses}

As for the average number of land uses, this appears to be related to geographical distribution (Figure 2). In the areas located in southern Italy, where traditionally numerous polycultures and associations between arboreal, herbaceous, and vegetable cultivations characterized the local agriculture, landscapes have a higher number of land uses (23 land uses). Also, the average number of land use according to altitude appears to follow a non-random distribution. In the hills there is an average higher value (21 land uses), precisely because there are areas still more suitable for traditional agricultural activities, while in mountain areas there are mainly historical pastoral and forest landscapes, traditionally characterized by a lower number of land uses (17 land uses). This data are partly confirmed by the average number of land uses by main type of landscape, with the highest values achieved by agricultural landscapes (22 land uses). Mixed-type landscapes reach lower values (16 land uses), but this should not be surprising, since these landscapes for the most part are characterized by silvo-pastoral activities. 


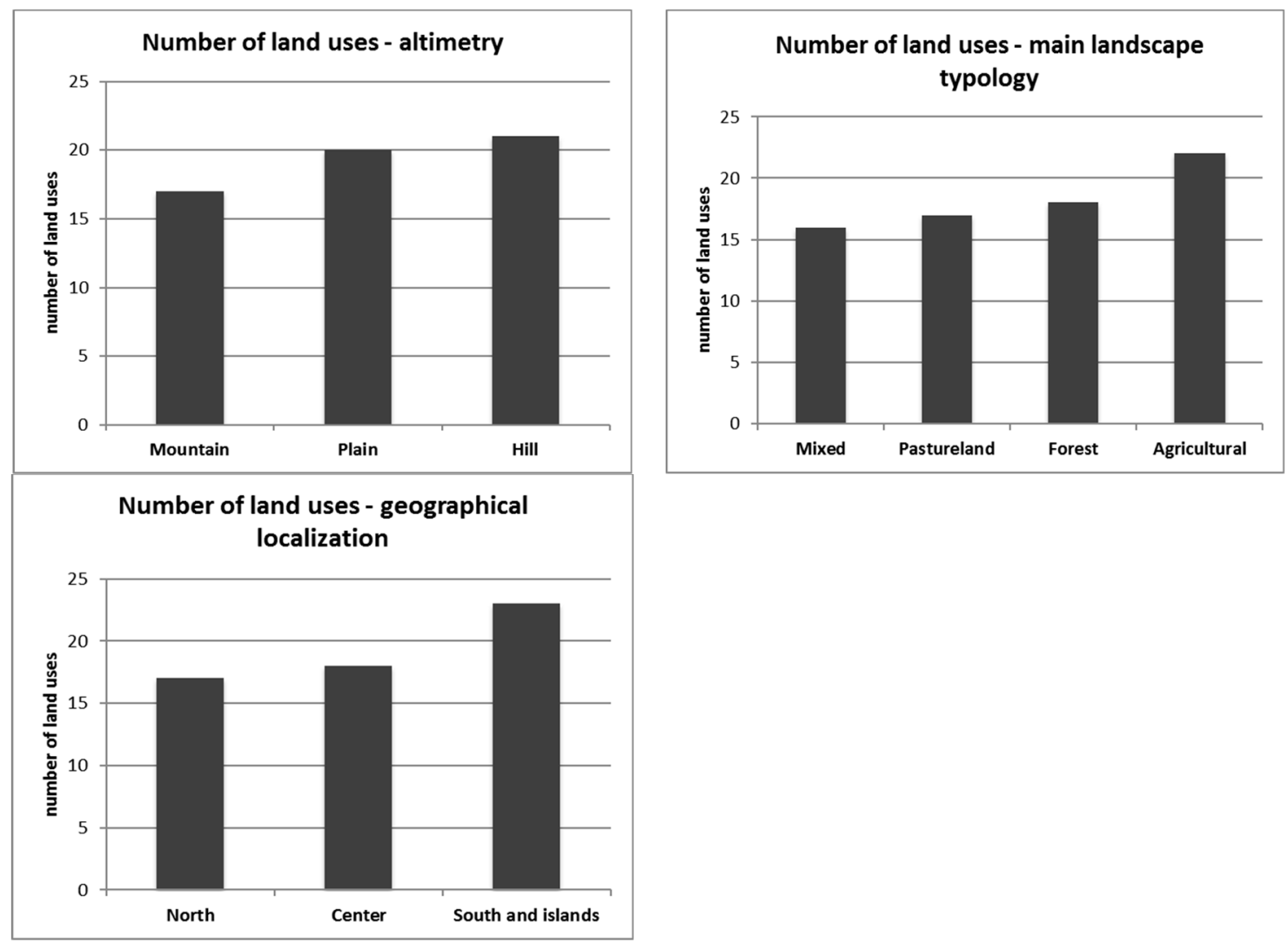

Figure 2. Average number of land use according to altitude, geographical distribution, and main typology of the landscape.

\subsection{Average Patch Size}

The average size of the patches is data directly related to the fragmentation and complexity of the landscape mosaic. The data obtained from the 123 historical landscapes show how the type of landscape is directly related to this index (Figure 3). In fact, forests and pastoral areas reach higher values of average patch size ( 5.9 and 5.5 ha, respectively) than agricultural areas (1.1 ha), which is confirmed by the correlation with altimetry; whereas in mountain areas, traditionally linked to silvo-pastoral landscapes, the average patch size is greater ( $5.5 \mathrm{ha}$ ) than that calculated for historical landscapes located in the plains (1.7 ha) and hills (1.9 ha). A correlation with geographical distribution is also noticed, as the areas located in the northern regions assume higher average values (2.6 ha). This can be explained by the fact that these regions retain a greater number of historical forest landscapes and because they have been more affected by the phenomenon of agricultural intensification that has led to an increase in the average patch size. The historical landscapes of the southern regions of Italy, especially the agricultural ones, are instead characterized by greater fragmentation and less intensification. 

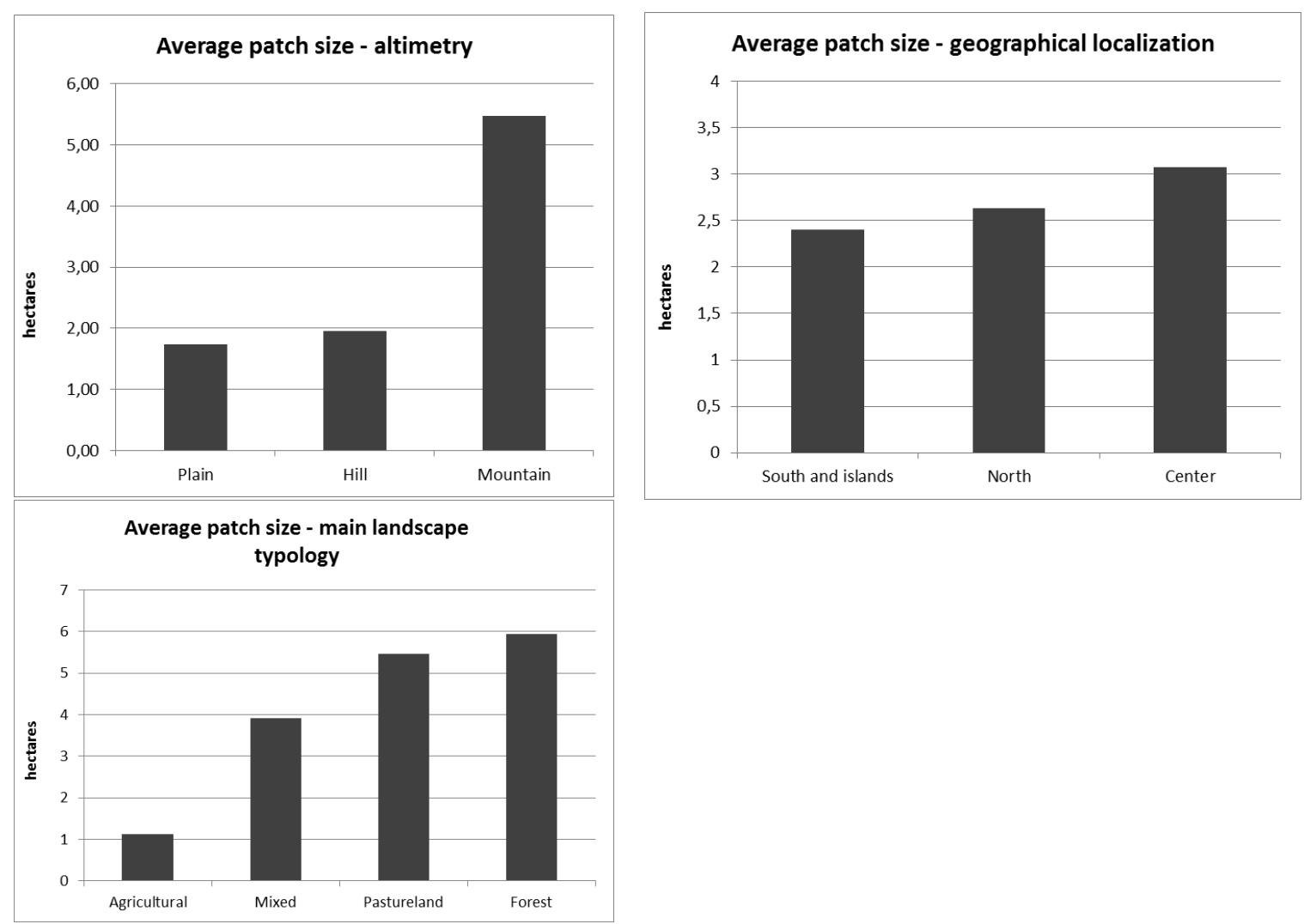

Figure 3. Average patch size according to altitude, geographical distribution, and main typology of the landscape.

\subsection{Edge Density}

The edge density is one of the applied indices used to evaluate the complexity of the shape of the patches. It is calculated as the ratio between the perimeter (in meters) and the surface (in ha) of each patch. The arithmetic average is calculated for each study area and taken as a reference. Higher values are typical of landscape mosaics characterized by smaller patches with irregular shapes and jagged edges, while lower values are frequent in contexts in which the patches are of a bigger and more regular shape. According to data calculated on the 123 historical landscapes (Figure 4), the higher values were found in agricultural landscapes (average of $970 \mathrm{~m} / \mathrm{ha}$ ), where in fact the patches have a smaller average size than in pastoral or forest landscapes. Regarding the altimetric distribution, the lowest values are found in areas located in the mountains $(756 \mathrm{~m} / \mathrm{ha})$. It follows that this index is strongly influenced by the average surface of the patches, more than their shape and the complexity of their shape. The agricultural patches are in fact more regular, while the forest ones usually have more jagged margins, and therefore the results should be opposite to what is instead measured. Thus, the application of this index to historical rural landscapes of so many different types does not provide significant and realistic information about the complexity of the shape of the patches that compose these landscape mosaics. 

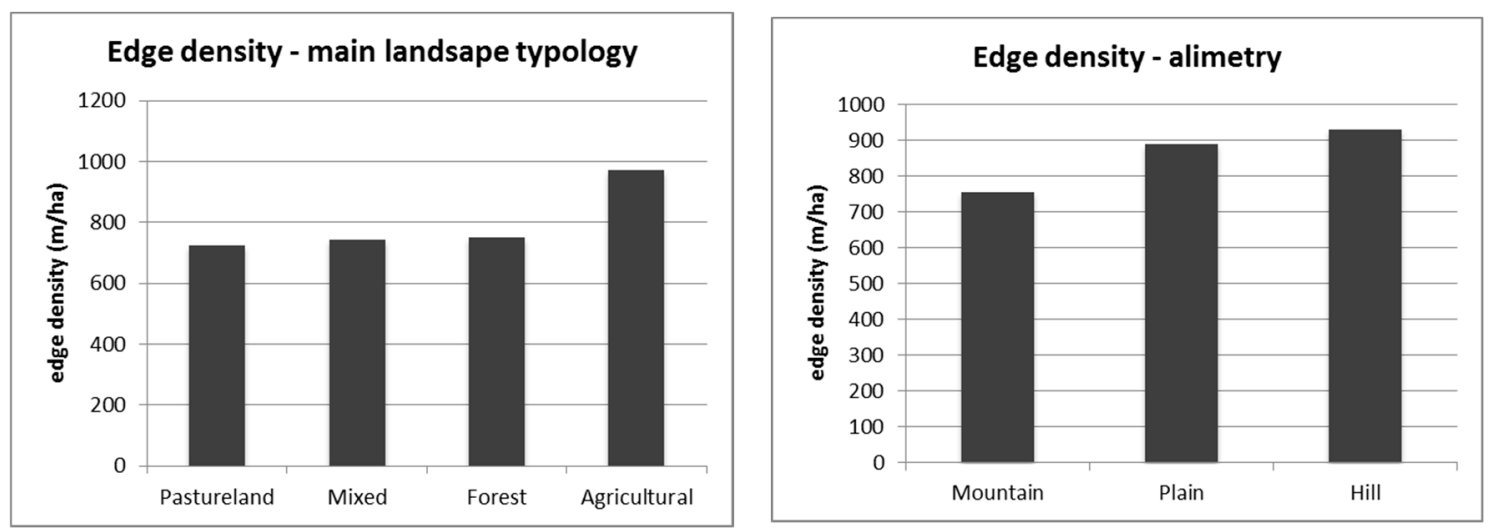

Figure 4. Edge density according to the main typology of landscape and altitude. The application of the edge density index to the 123 different study areas led to mixed, and sometimes opposite, results.

\subsection{Historical Landscape Typologies}

Additional interesting data was given by the results of the analysis of the distribution of the main types of landscape in relation to the altimetry and geographical localization (Figure 5). Agricultural landscapes, the most widespread typology, are mainly distributed in the plains and hills, where agricultural activities are easier to conduct due to geomorphologic conditions; at the same time they are the most represented type in the north, south, and center, with a majority in southern Italy. Forests landscapes are instead more represented in the mountains and hills, as well as in the northern and southern regions. Central regions show a good presence of mixed landscapes, very common even in mountain areas. Pastoral landscapes, which are found mainly in the northern and southern regions, are also very common in the same mountain areas.

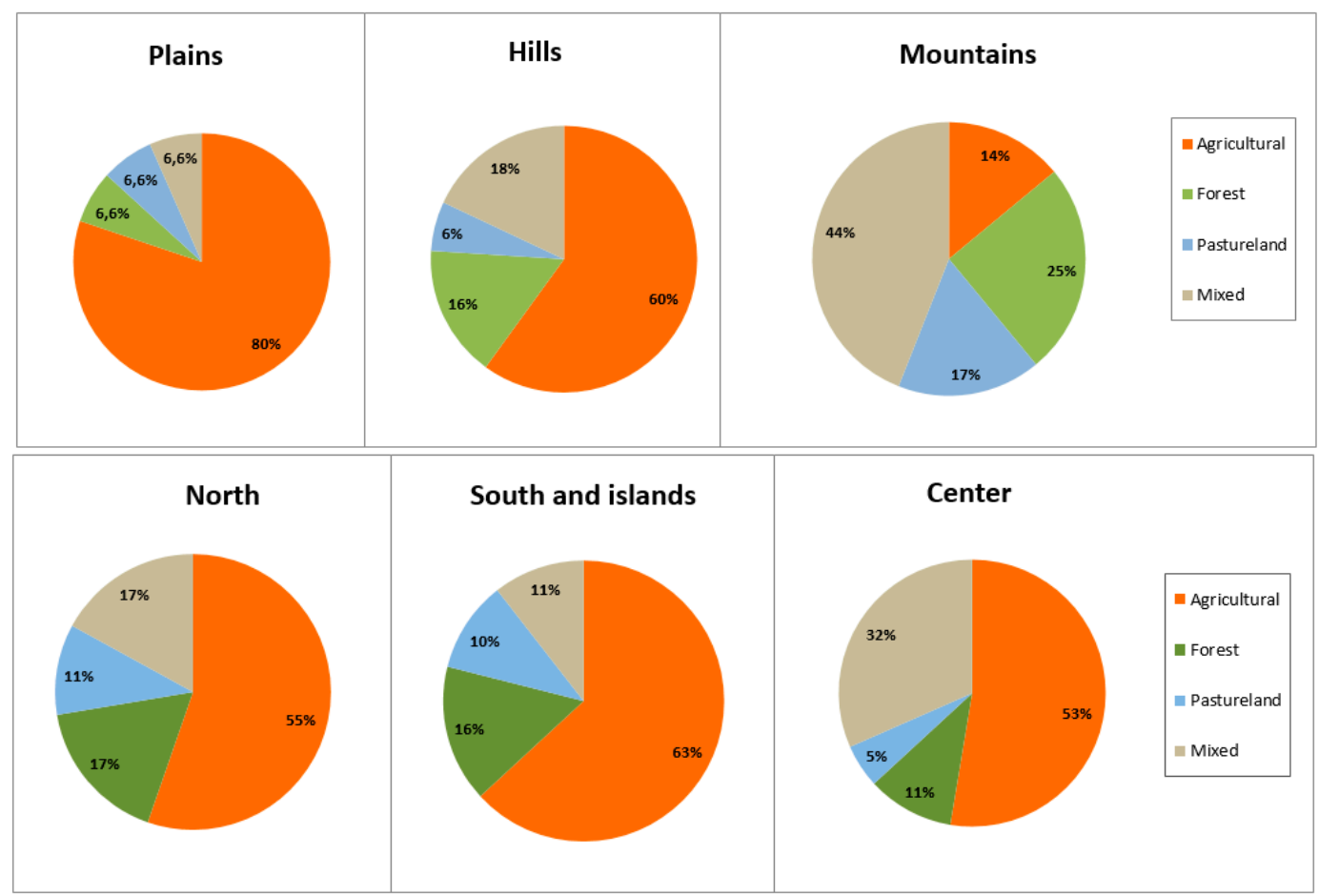

Figure 5. The main typology of landscapes according to altitude and geographical distribution. Agricultural landscapes are mainly located in the plains and hills. Mountains are mainly characterized by mixed historical landscapes, that are also common in the central part of Italy, even if agricultural ones are always the most widespread according to geographical distribution. 


\subsection{Level of Integrity of the Historical Landscapes}

The integrity level of the historical rural landscapes seems to be strictly correlated more to the geographical location rather than the altimetric one (Figure 6). The landscapes of the central regions preserve a higher level of integrity, with an average level equal to 4.4. This is due to the fact that the agro-silvo-pastoral activities of these regions have been less affected by abandonment, intensification, or degradation, compared to other Italian regions. In the southern regions (3.7), in fact, there are many phenomena of deterioration of the historical landscapes, mainly related to abandonment and in many cases to the uncontrolled expansion of urban areas. In the northern regions (3.3), on the other hand, the intensification phenomenon has often led to the almost total disappearance of the historical landscapes in the plains, while abandonment has mainly threatened the historical landscapes of the mountains. The historical landscapes of the central regions still appear to be characterized by traditional agricultural forms, a complexity made of small woods and different historical agricultural land uses, that in many cases have remained unaltered.

Regarding the distribution of integrity according to the type of landscape, forest landscapes appear to be the most compromised (3.5). This derives from the fact that such landscapes, in order to be considered historically intact, must preserve a specific composition of the same tree species of the past. Due to the disappearance of traditional forms of use, the forest structure has changed and thus lost the characteristics of its historical significance. In the case of the pine wood of San Vitale, a pine of Roman origin, the pure pine forest, no longer regularly managed as it was for centuries, is gradually being replaced by mixed forests of conifers and deciduous trees that will lead to the formation of broad-leaved woods. Old pine trees are no longer replaced, and the pine cannot naturally renew itself under a dense cover.

From the analysis of the data on historical landscape integrity, there does not appear to be any correlation to altitude, since the difference between the higher average value (4.0 for the mountains) and the lower value ( 3.6 for the hills) is not significant.
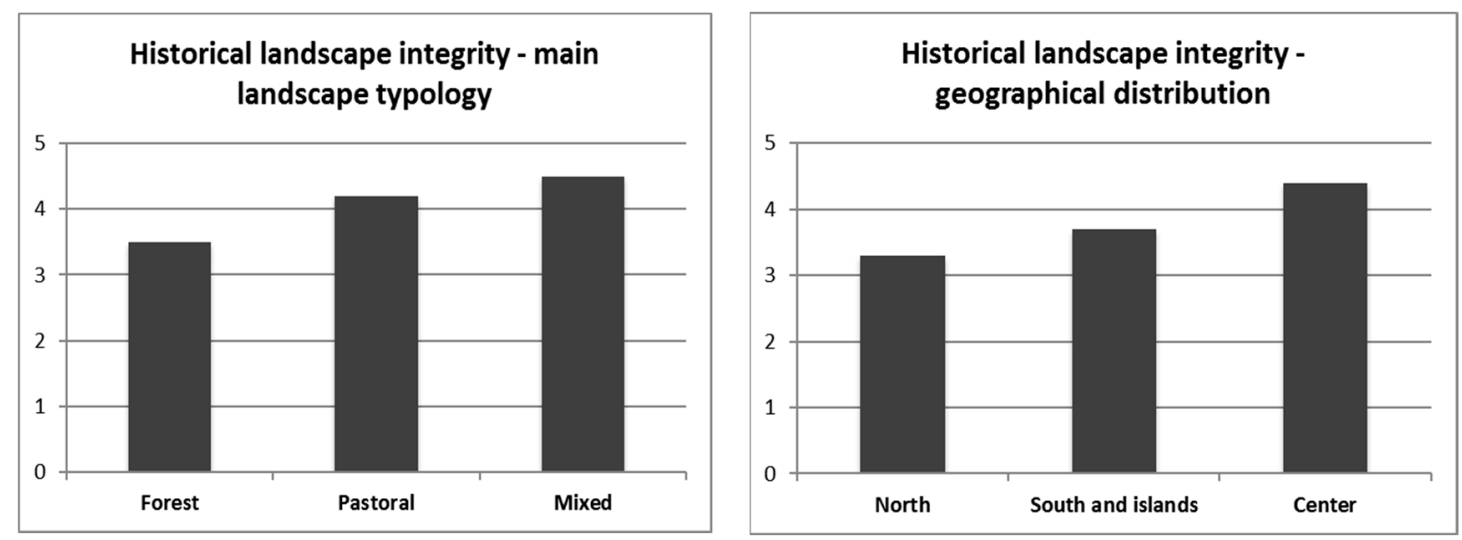

Figure 6. Average level of historical landscape integrity, according to the main typology of the landscape and geographical distribution, showed that landscapes located in central Italy have higher average values (4.4) of landscape integrity.

\subsection{Protected Areas and Areas Affected by Landscape Restrictions}

Additional significant data derive from the analysis of different types of protected areas (national parks, regional parks, natural reserves, UNESCO WHL sites, Natura 2000) and landscape restriction. Landscape restriction is regulated by two national laws, the n. 1497 of 1939 and n. 431 of 1985, that impose protection on particular types of territories (i.e., areas closer than $150 \mathrm{~m}$ to rivers, areas above $1600 \mathrm{~m}$ a.s.l. for the Alpine mountains, volcanoes, national parks and reserves, and forests). Over $96 \%$ of the areas are subjected entirely or in part by protected areas or landscape restriction (Figure 7). 
Regarding the protected areas, $39.3 \%$ of the total surface of the 123 historical landscapes is included in protected areas. The results show that the presence of Natura 2000 areas (site of community importance (SCI) and special protection area (SPA)) is particularly frequent; over 40 areas are affected by this type of protection, while all other types of protected areas are less frequent and 38 landscapes are not included in any kind of protected areas. Considering landscape restrictions, $52.6 \%$ of the total surface is subjected to one or both of the restriction laws. An analysis of the vulnerabilities [2\} showed that ordinary legislation cannot guarantee the conservation of historical rural landscapes, since the main orientations of the protected areas tend to protect the "natural" habitats and biodiversity instead of the biodiversity linked to traditional agricultural activities. These restrictions proved to be effective in opposing urban spread but seem to be inadequate in protecting the characteristics of historical rural landscapes, since these laws and forms of protections were developed in order to preserve environmental characteristics more than cultural and historical ones.

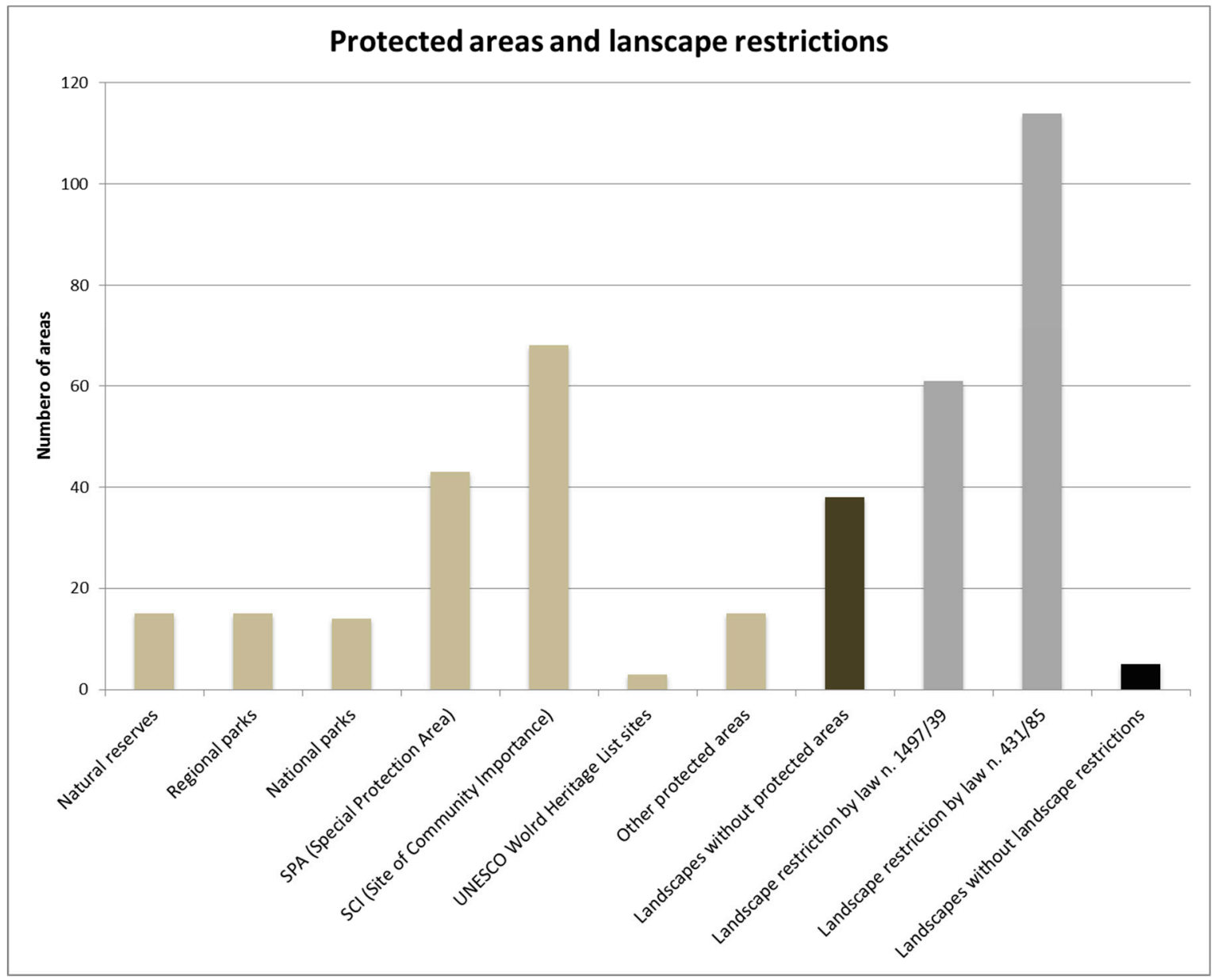

Figure 7. Number of historical landscapes affected by protected areas or by landscape restrictions. These different protection forms were mainly developed in order to preserve environmental characteristics more than cultural and historical ones.

\section{Results and Discussion of the Monitoring}

The analysis of the transformations compared the land uses of the first surveys (2007-2010) to recent orthophotos or satellite images (2015-2018) for all 123 areas included in the catalogue, highlighting that $27 \%$ of the areas (equal to 33 areas) have undergone changes that involved at least $5 \%$ of their surface. Values lower than $5 \%$ were not considered significant, since they involve very small surfaces compared to the total extension, so they cannot be considered important. In total, $48 \%$ of the areas that have undergone significant changes were located in the hills, $40 \%$ in the plains, and $12 \%$ in 
the mountains. Regarding the main landscape typology, $72 \%$ is classified as agricultural landscape, $24 \%$ as mixed landscape, and $3 \%$ as landscapes mainly composed of pastures. Additionally $51 \%$ of these areas are located in the northern part of Italy, $42 \%$ in the central regions, and $6 \%$ in the south or islands. All the following graphs and data will therefore refer to these 33 areas. Considering the overall results of the 33 areas (Figure 8), the main changes were related to agricultural activities. From one side traditional cultivations have been affected by intensification, while from the other side they have been affected by abandonment (extensification and forestation).

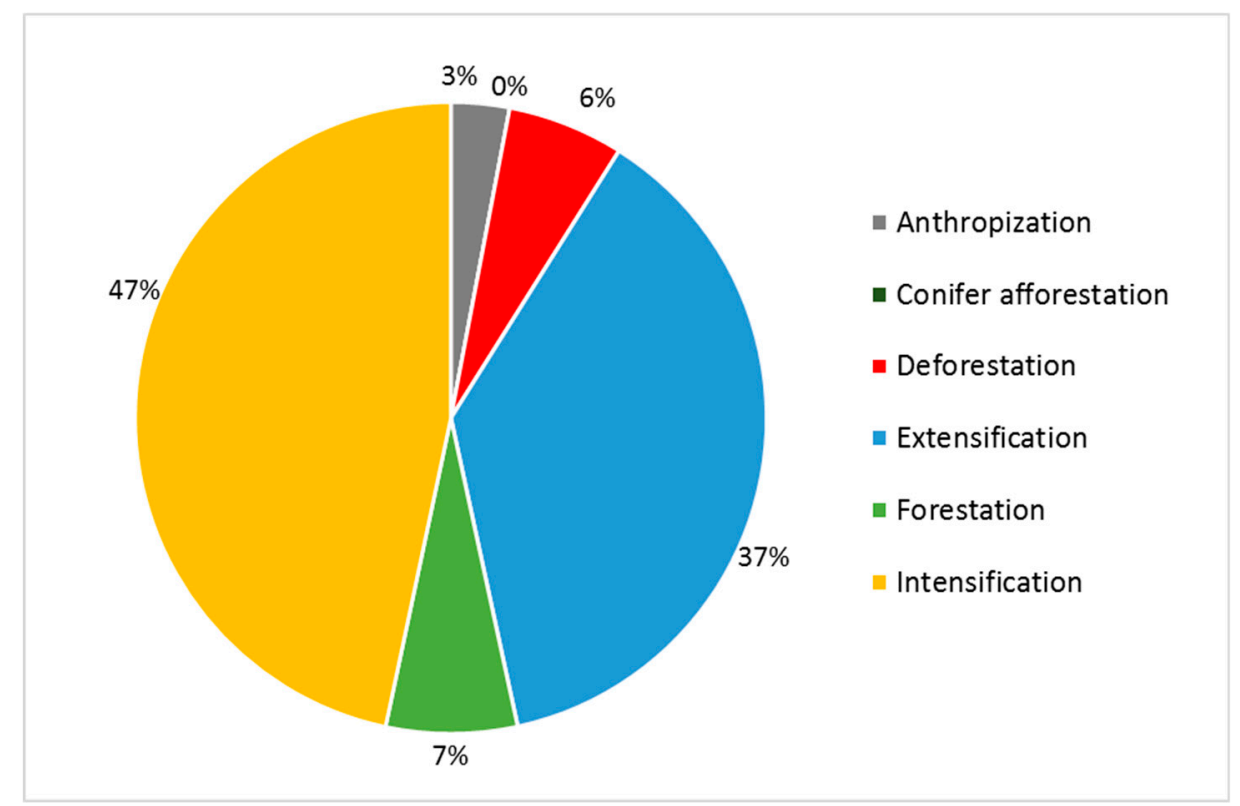

Figure 8. Results of monitoring for 33 areas that have undergone land use changes on more than $5 \%$ of their surface.

In general, the number of land uses, over the analyzed period of time, grew by $18 \%$, while at the level of the average surface of the patches there was an increase of $8 \%$ and a growth in the values of edge density of almost $5 \%$. The average level of integrity, established on the basis of the comparison between the average class of integrity of the areas in the past and the current one, decreased overall by $5 \%$. In terms of dynamics, the total area left unchanged, in the 33 study areas, is almost equal to 40,000 ha over a total area of 43,857 ha (about $90 \%$ ). The second dynamic in terms of occupied surface, is intensification ( $4.5 \%$ of the total area), followed by extensification ( $3.6 \%$ of the total area).

Anthropization and forestation have registered extremely small percentages (together they do not reach $2 \%$ of the total surface).

The comparison between the past and the present highlights how, considering the different altimetric zones, the average number of land uses has increased, especially in the hills (almost $+20 \%$ ). This is most evident in the pastoral landscape typology. For example, in the area of the Magredi di Vivaro (Friuli Venezia Giulia), the new land uses correspond in part to anthropic areas (photovoltaic) and partly to agricultural land uses (pastures, meadows, vineyards). In the areas located in southern Italy, no major changes have been recorded in the average number of land uses, while in the north and in the center, there was an increase of $18 \%$ and $19 \%$, respectively (Figure 9).

Regarding the complexity of the landscape mosaic, the areas located in the plains and hills did not show substantial changes in the average number and average surface of the patches (Figure 10). The areas located in the mountains, on the other hand, underwent a process of landscape simplification, as evidenced by the reduction in the average number of patches $(-10 \%)$ and by the increase of the average size $(8 \%)$. Concerning the level of fragmentation, measured by the application of the edge density index, an increase was shown in the mountains and plains, where the values grew by $4 \%$ and $8 \%$, respectively (Figure 11). 

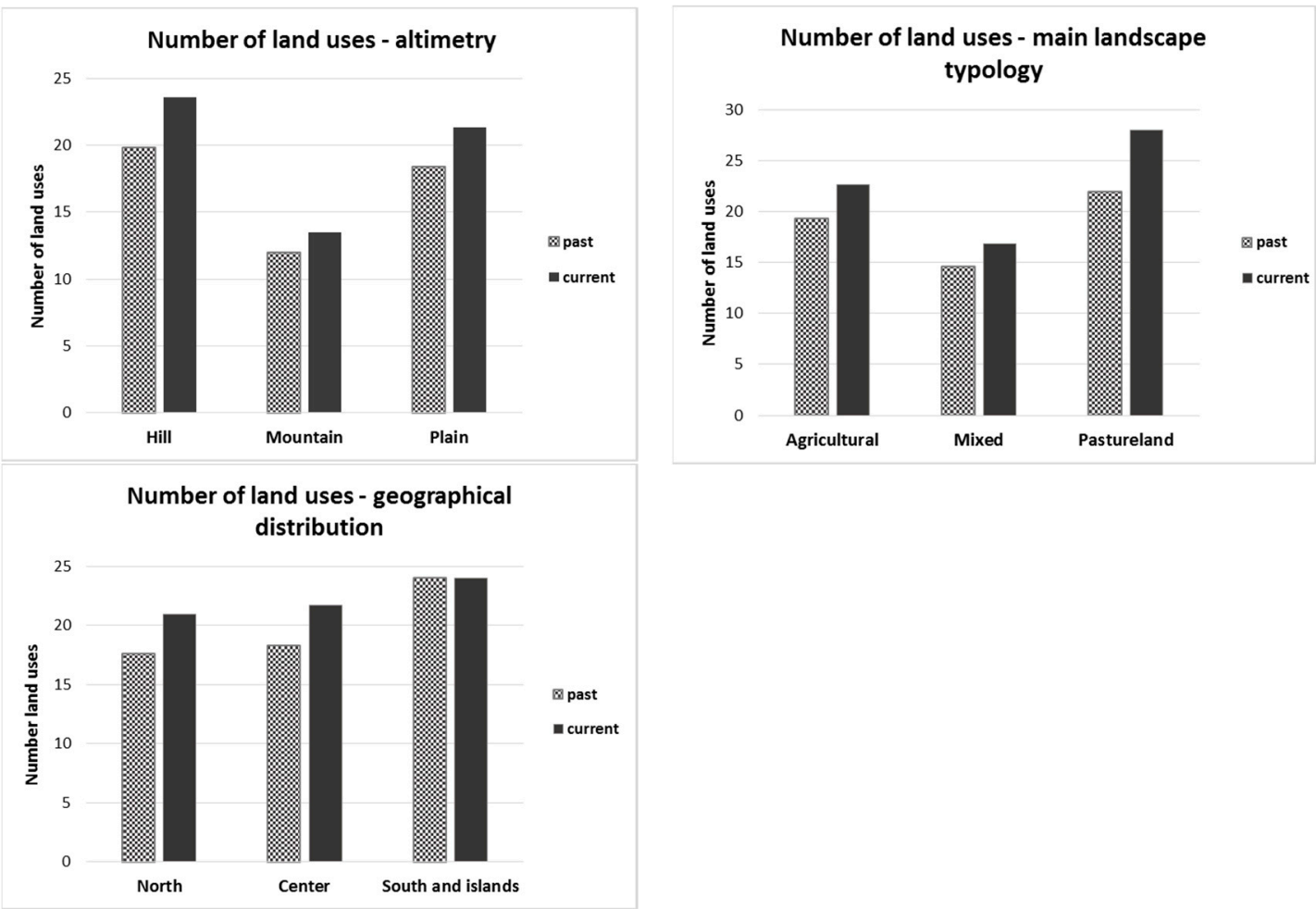

Figure 9. Comparison between the average number of past and current land uses for different altimetry, landscape types, and geographical localization. The increase of land uses is particularly evident for the hills, for pastoral land typology, and for northern and central Italy.
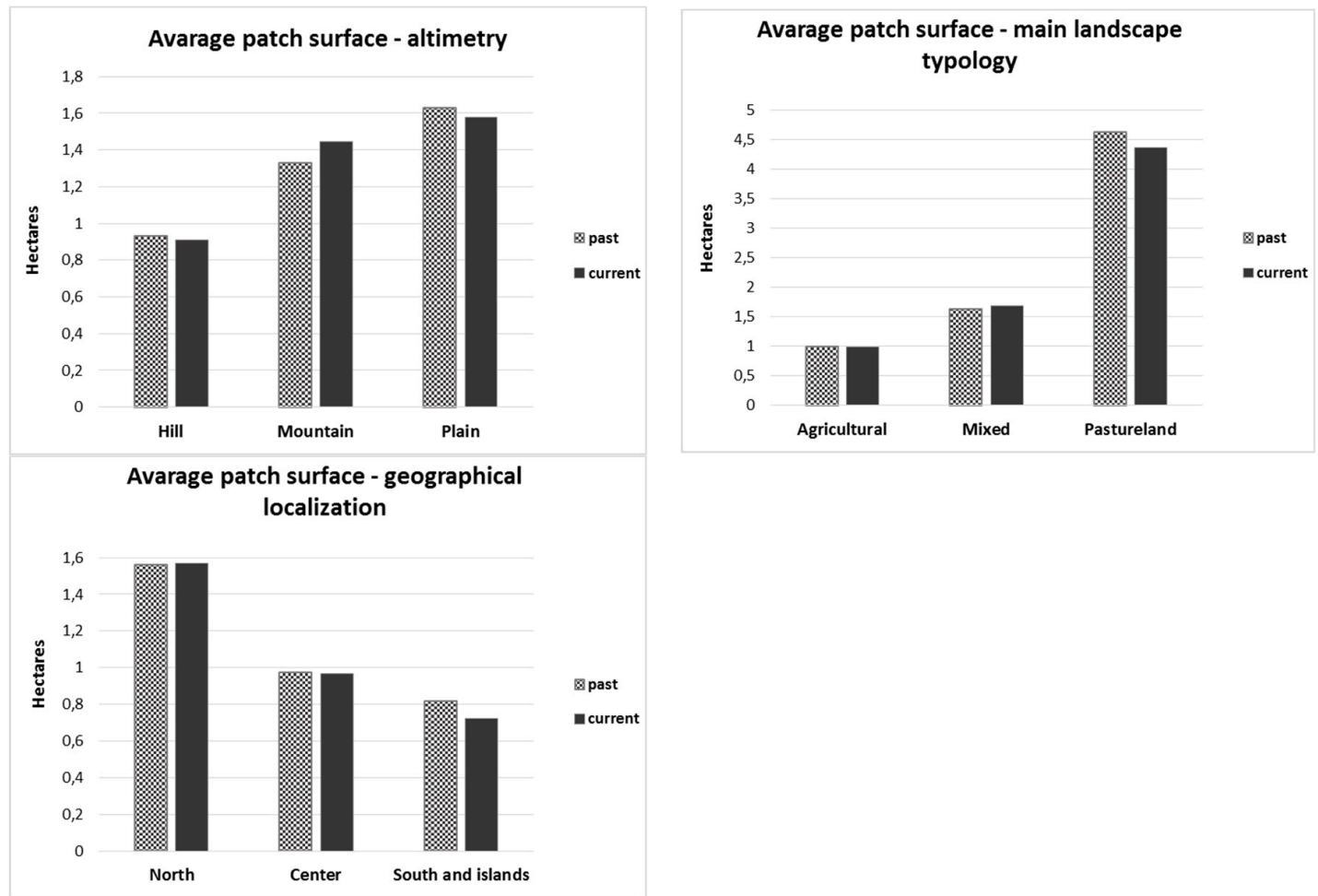

Figure 10. Comparison between the average size of past and current patches for different altimetry, landscape types, and geographical localization. Areas located in the mountains suffered a process of landscape simplification, as shown by the increase of the average surface. 


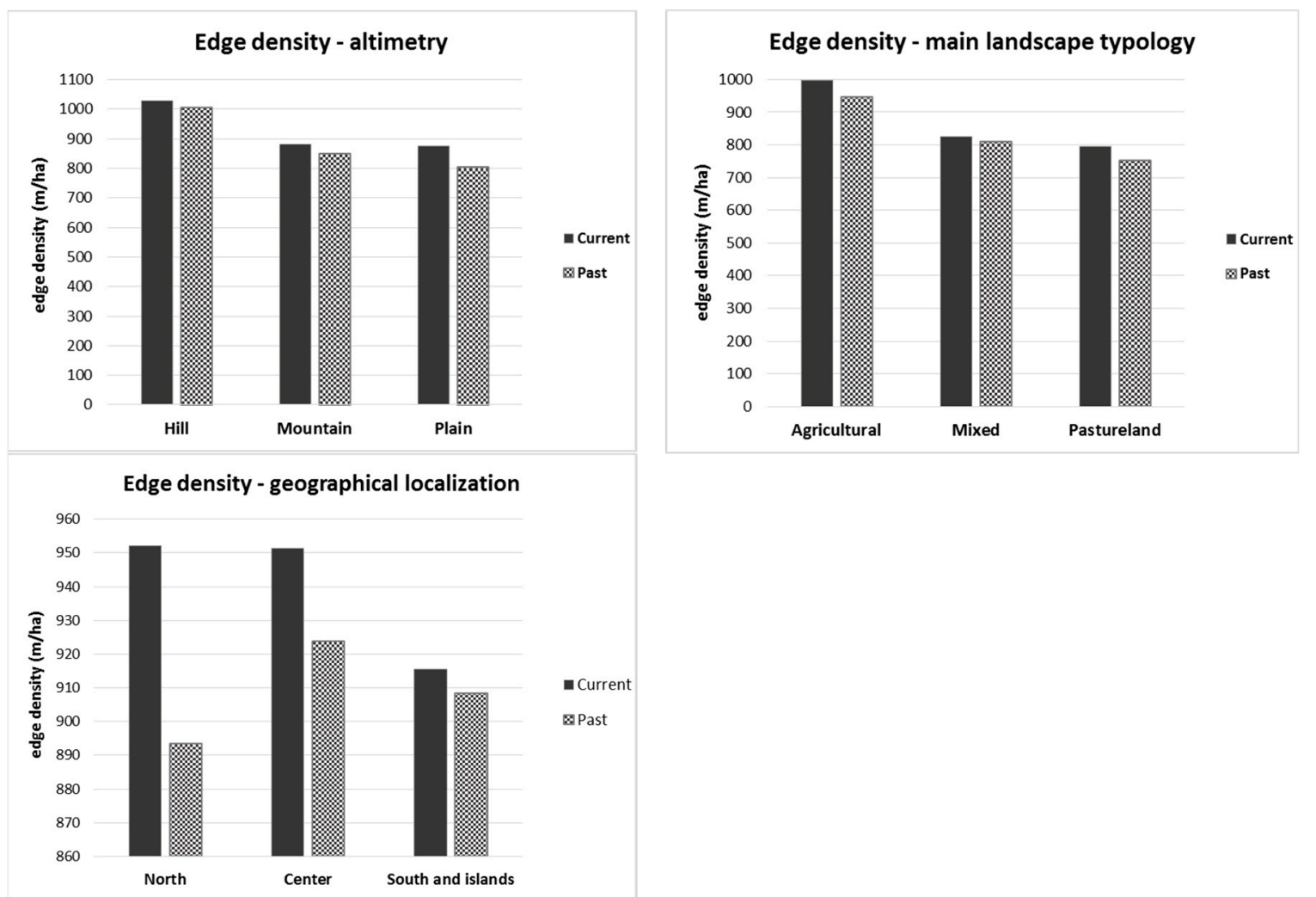

Figure 11. Comparison between the average value past and current edge density for different altimetry, landscape types, and geographical localization.

The predominantly agricultural and mixed landscapes have not undergone great changes regarding the level of complexity of the landscape mosaic, as the values of the average number and average patch surface are almost unchanged. On the other hand, pastoral landscapes showed an increase in the degree of fragmentation as evidenced by the increasing trend in the average number of patches $(6 \%)$ and the decreasing trend in the average patch surface $(-5.6 \%)$. Evaluating the level of complexity of the landscape mosaic according to geographical localization, the landscapes located in northern and central Italy did not show great changes, exhibiting almost unchanged values of the average number and average patch surface. Increases in the level of complexity of the landscape mosaic are recorded in the south, where the average number of patches increased by $8 \%$ and the average patch surface decreased by $12 \%$.

Also, the values of edge density testify to the increase of landscape fragmentation in agricultural $(5.4 \%)$ and pastoral (5.6\%) landscapes, while mixed type landscapes did not undergo substantial changes in the fragmentation of the landscape mosaic. According to geographical localization, the value of edge density in the south was unchanged, while it increased in the north $(6 \%)$ and center $(3 \%)$.

The average level of integrity (Figure 12) is almost the same as in the past in the hills, while it decreased in the mountains $(-4 \%)$ and plains $(-9 \%)$. According to the main landscape typology, there were no variations in the average level of integrity for pastoral landscapes, while for agricultural and mixed ones, decreases of respectively $-4 \%$ and $-6 \%$ were recorded. Finally, the level of integrity according to geographical distribution showed a negative trend for the north $(-6 \%)$, center $(-5 \%)$, and especially the south $(-14 \%)$. 


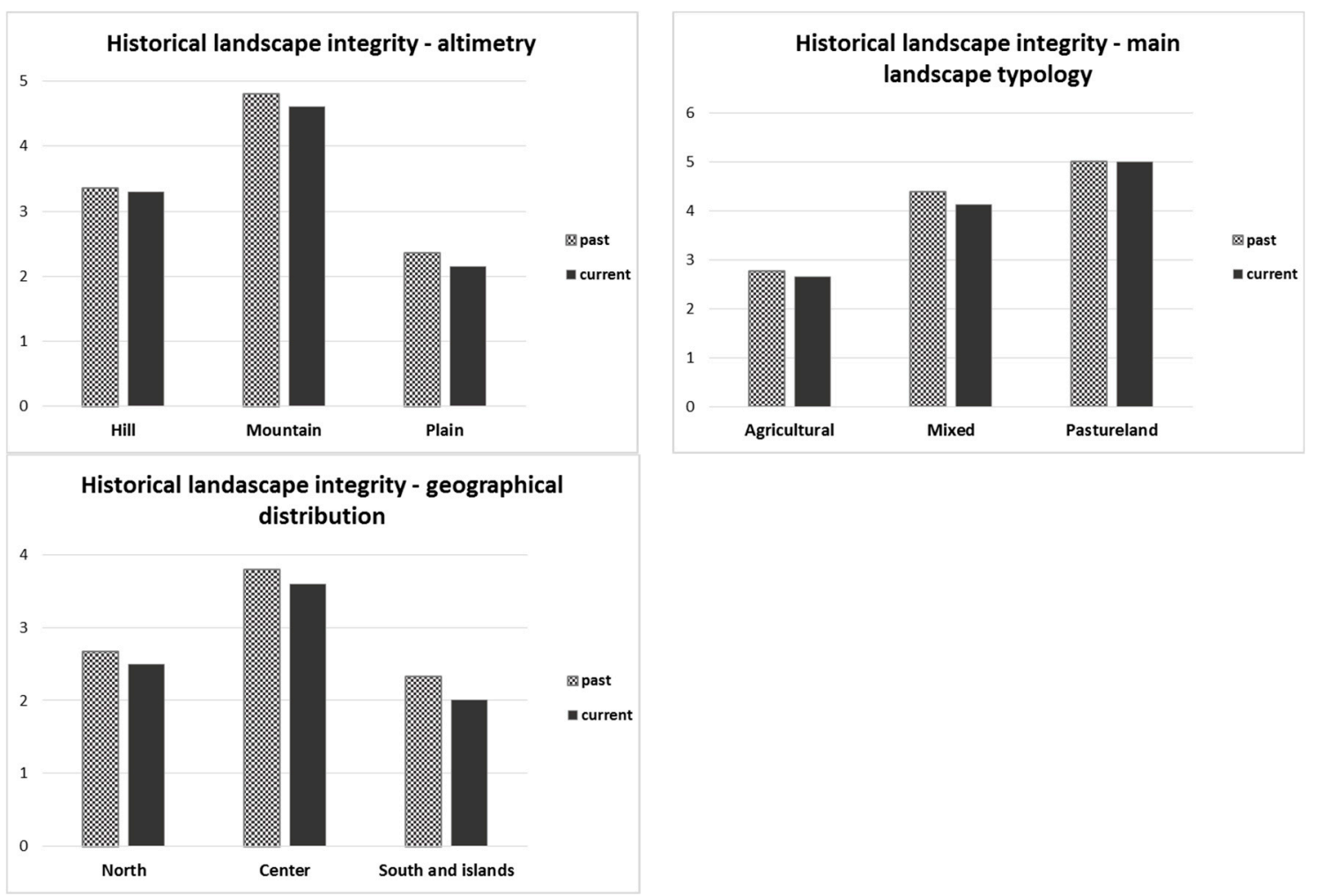

Figure 12. Comparison between the average level of past and current landscape integrity for different altimetry, landscape types, and geographical localization.

Comparing the total surfaces involved by the different types of landscape dynamics, "unchanged" is predominant in the plains, where the unchanged surface is greater by almost $10 \%$ compared to the mountains and $25 \%$ compared to the hills. The areas located in the north presented higher values of "unchanged" compared to the center and the south, as was the case for pastoral landscapes.

The dynamics of intensification mainly involved mountain areas; from a comparison between the total surfaces involved by this transformation, the mountains show a total surface greater than $28 \%$ compared to the plains and 50\% compared to the hills. Finally, in pastoral landscapes the intensification manifested itself more than in mixed $(+29 \%)$ and agricultural landscapes $(+88 \%)$.

Extensification mostly affected the areas located in the plains, whose total surface was double compared to the hills and almost three times that of the mountains. Extensification also prevailed in the northern regions and in pastoral landscape types.

Forestation, anthropization, and conifer afforestation affected smaller areas, less than $2 \%$ of the total surface. Forestation can mainly be found in the hills, double the surface of the plains and six times more than the mountains. Regarding landscape types, forestation mainly occurred in agricultural and mixed landscapes, while, considering geographical localization, it is more spread in the center and north; in the south it is almost absent. The areas affected by anthropization are of the same size in the hills and plains, and slightly higher in the mountains.

\section{Conclusions}

The analysis of the landscapes of 123 areas carried out on 2007-2010 orthophotos, represents the first database at national level of historical rural landscapes. The data collected developing the first land use layer, highlighted the differentiation in landscape characteristics, according to altimetric and geographical localization and land use typology. It is possible to identify some characteristics which allow a possible grouping in homogeneous classes. Agricultural activities are mainly located in hilly and flat areas, where agricultural activities are more economically profitable. These areas are characterized by a fine-grain structure of the landscape mosaic and by high complexity, with an 
average patch size equal to 1.12 ha and an average number of land use equal to $22 \mathrm{ha}$. Mountains are mainly characterized by mixed landscapes, with grazing, forestry, and agricultural activities often distributed equally. Here agriculture is practiced on small surfaces by smallholder farmers, but the structure of the landscape consists on average of larger patches ( $5.5 \mathrm{ha}$ ) due to forests and pastures. Mixed landscapes are also common in the central part of Italy, where traditionally the landscape consists of the coexistence of agro-silvo-pastoral activities due to the organization of the territory in small farms (poderi). Overall, it is possible to state that the Italian historical landscapes are characterized by a high number of different cultivations and land uses, often carried out on small patches, as a consequence of the traditional management and high-fragmentation of the properties. The high-quality products that come from these cultivations and from animal husbandry, that in some cases are found only on some tens of ha in the whole national territory, justify and guarantee their maintenance, even if they are always productions that risk disappearing in the near future. The results are landscape mosaics with a high complexity and diversity of the landscape structure. This complexity is a fundamental component of the biocultural diversity expressed by these landscapes, which include animal and vegetal species related to the traditional agricultural practices, as also described by the FAO GIAHS program.

The same areas were analyzed on more recent orthophotos (2015-2018) in order to perform the dynamics analysis. The analysis showed that 33 of 123 areas have undergone significant changes regarding land use, involving a surface equal to or greater than $5 \%$ of the total surface of the study area. The past and current data of these 33 areas affected by more substantial changes were therefore compared.

The results of the comparison show, in general, a good maintenance of the quality of the historical landscapes. Even if $27 \%$ of the 123 areas have undergone significant transformations in their territory in the last years, the majority of the areas still largely retain the same land uses of about 10 years ago.

The number of land uses in the analyzed time frame increased, as well as the values of edge density and the average values of Hill's diversity number. The values of the level of integrity, on the other hand, decreased compared to the past. Through the evaluation of these indexes, it is possible to verify the characteristics of the landscape mosaic and the maintenance of its level of fragmentation and complexity.

The results of the indexes were evaluated by subdividing the 33 landscapes according to the altimetry, geographical localization, and main land use typology. In the latter case, the absence of forest landscapes is evident, and is due to the fact that forests are affected by minor changes since they are strongly protected by national and regional laws, less affected by human activities, and also because the time needed for the evolution of a forests is longer. The most common type of landscape that underwent transformations on more than the $5 \%$ of the surface was agricultural landscape, followed by mixed landscapes, and finally landscapes mainly dedicated to grazing. Due to the evolution of mechanization and to changes in agricultural policies, the agricultural sector is most affected by land use changes in a short period.

Over the last years, the 33 areas witnessed a greater diversification of land uses, probably also due to the better quality of the recent orthophotos that allowed for greater detail. The number of patches, in most cases, increased, and so the complexity and fragmentation of the landscapes slightly improved. The average surface of the patches remained constant or sometimes decreased, showing an increase in the level of landscape fragmentation. The level of integrity, a fundamental index to measure the maintenance of the historic characteristic of the landscape, generally decreased. This index is based on the surface of the land uses considered to be of historical interest in the study area, therefore, its decrease means that there was a reduction in land uses of historical interest. In any case, this index tends to underestimate the actual level of conservation of the historical landscape.

In general, the monitoring of 123 areas highlighted positive trends maintaining their historical and peculiar characteristics. The 33 areas where transformations are considered significant still largely maintain the characteristic features for which they are considered representative of historical landscapes in national territory. Despite this, it is necessary to point out that a transformation on $5 \%$ of the territory 
in such a short period of time, in the long term can lead to transformations that can deeply modify the characteristic features. Further monitoring is needed in the following years to assess the level of maintenance of historical landscapes.

This database is a fundamental source of information and data related to the study and monitoring of national historical rural landscapes, both because it includes different types of landscapes in different environmental situations, and because the areas are spread across the whole nation. A regular monitoring of these areas will evaluate and measure the most important changes and effectiveness of rural policies, and the effect of climatic and other environmental changes, to identify the places where the historical landscape is intact or more susceptible to deterioration, as well as the causes of degradation and possible initiatives to be taken to counteract them.

Most of the identified areas have the necessary characteristics to be included in the National Register of Historical Rural Landscapes and in the FAO GIAHS program. Ten of these areas are already inscribed in the register, one in the UNESCO WHL and two in the FAO GIAHS program, thanks to an agreement between the Italian Ministry of Food, Agricultural and Forest Policies and FAO. In view of the general trends of the Italian rural landscapes, especially abandonment and the reforestation of cultivated land, as already explained, an exception to the protection laws allows the landscapes included in the register to remove secondary forests and restore previous cultivations.

Author Contributions: Conceptualization, M.A. and A.S.; methodology, A.S.; investigation, A.S., F.E., F.C., and M.V.; writing, A.S., F.E., F.C., and M.V.; supervision, M.A.

Funding: This research was funded by the AICS (Italian Agency for Development Cooperation) project "GIAHS building capacity".

Conflicts of Interest: The authors declare no conflicts of interest.

\section{References}

1. Agnoletti, M.; Rotherham, I.D. Landscape and biocultural diversity. Biodivers. Conserv. 2015, 24, $3155-3165$. [CrossRef]

2. Agnoletti, M. (Ed.) The Italian historical rural landscape. In Cultural Values for the Environment and Rural Development; Springer: Dordrecht, The Netherlands, 2013.

3. Agnoletti, M. Rural landscape, nature conservation and culture: Some notes on research trends and management approaches from a (southern) European perspective. Landsc. Urban Plan. 2014, 126, 66-73. [CrossRef]

4. Grove, A.T.; Rackham, O. The Nature of Mediterranean Europe. An Ecological History; Ehrhardt, M., Ed.; Yale University Press: New Haven, CT, USA, 2001.

5. Pitte, J.R. Histoire Du Paysage Francais II; Pluriel: Paris, France, 1994.

6. Antrop, M. Sustainable landscapes: Contradiction, fiction or utopia. Landsc. Urban Plan. 2006, 75, 187-197. [CrossRef]

7. UNESCO-CBD. Joint Program between Biological and Cultural Diversity. Florence Declaration on the Links between Biological and Cultural Diversity. Florence (Italy). 11 April 2014. Available online: https://www.cbd.int/ portals/culturaldiversity/docs/21040410-declaration-florence-en.pdf (accessed on October 2019).

8. Agnoletti, M.; Tredici, M.; Santoro, A. Biocultural diversity and landscape patterns in three historical rural areas of Morocco, Cuba and Italy. Biodivers. Conserv. 2015, 24, 3387-3404. [CrossRef]

9. Baudry, J.; Baudry-Burel, F. La mesure de la diversité spatiale. Relation avecla diversité spécifique. Utilisation dans les évaluations d'Impact [The measure-ment of the spatial diversity. Relationship with specific diversity. Use in impactassessments]. Acta Ecol. Oecol. Appl. 1982, 3, 177-190.

10. Cevasco, R.; Moreno, D. The historical roots of biodiversity. In Historical Rural Landscapes. Cultural Values for the Environment and Rural Development; Agnoletti, M., Ed.; Springer: Dordrecht, The Netherlands, 2012.

11. Naveh, Z. Culture and landscape conservation: A landscape-ecological per-spective. In Ecology Today: An Anthology of Contemporary Ecological Research; Gopal, B., Ed.; International Scientific Publications: New Delhi, India, 1998; pp. 19-48. 
12. Moreira, F.; Russo, D. Modeling the impact of agricultural abandonment and wildfires on vertebrate diversity in Mediterranean Europe. Landsc. Ecol. 2007, 22, 1461-1476. [CrossRef]

13. Wilson, G.A. From productivism to post-productivism ... and back again? Exploring the (un)changed natural and mental landscapes of European agriculture. Trans. Inst. Br. Geogr. 2001, 26, 77-102. [CrossRef]

14. Kristensen, L.S.; Thenail, C.; Kristensen, S.P. Landscape changes in agrarian landscapes in the 1990s: The interaction between farmers and the farmed landscape. A case study from Jutland, Denmark. J. Environ. Manag. 2004, 71, 231-244. [CrossRef]

15. Conti, G.; Fagarazzi, L. Sustainable mountain development and the key issue of abandonment of marginal rural areas. Eur. J. Plan. 2004, 20, 1-19.

16. Agnoletti, M. The development of a historical and cultural evaluation approach in landscape assessment: The dynamic of Tuscan Landscape between 1832 and 2004. In The Conservation of Cultural Landscapes; Agnoletti, M., Ed.; CAB International: Wallingford, UK; New York, NY, USA, 2006.

17. Evans, N.J.; Morris, C. Towards a geography of agrienvironmental policies in England and Wales. Geoforum 1997, 28, 189-204. [CrossRef]

18. Marsden, T.; Murdoch, J.; Lowe, P.; Munton, R.; Flynn, A. Constructing the Countryside; UCL Press: London, UK, 1993.

19. Hadjimichalis, C. Imagining rurality in the new Europe and dilemmas for spatial policy. Eur. Plan. Stud. 2003, 11, 103-113. [CrossRef]

20. Walford, N. Productivism is allegedly dead, long live productivism. Evidence of continued productivist attitudes and decision-making in South-East England. J. Rural Stud. 2003, 19, 491-502. [CrossRef]

21. Verhulst, J.; Báldi, A.; Klein, D. Relationship between land-use intensity and species richness and abundance of birds in Hungary. Agric. Ecosyst. Environ. 2004, 104, 465-473. [CrossRef]

22. Macdonald, D.; Crabtree, J.R.; Wiesinger, G.; Dax, T.; Stamou, N.; Fleury, P.; Gutierrez Lazpita, J.; Gibon, A. Agricultural abandonment in mountain areas of Europe: Environmental consequences and policy response. J. Environ. Manag. 2000, 59, 47-69. [CrossRef]

23. Baldock, D.; Beaufoy, G.; Brower, F.; Godeschalk, F. (Eds.) Farming at the Margins. In Abandonment or Redeployment of Agricultural Land in Europe; IEEP London/Agricultural Economics Research Institute: The Hague, The Netherlands, 1997.

24. Pinto-Correia, T. Future development in Portuguese rural areas: How to manage agricultural support for landscape conservation. Landsc. Urban Plan. 2000, 50, 95-106. [CrossRef]

25. Wu, Q.; Li, H.Q.; Wang, R.S.; Paulussen, J.; He, Y.; Wang, M.; Wang, B.; Wang, Z. Monitoring and predicting land use change in Beijing using remote sensing and GIS. Landsc. Urban Plan. 2006, 78, 322-333. [CrossRef]

26. Zomeni, M.; Tzanopoulos, J.; Pantis, J.D. Historical analysis of landscape change using remote sensing techniques: An explanatory tool for agricultural transformation in Greek rural areas. Landsc. Urban Plan. 2008, 86, 38-46. [CrossRef]

27. De Aranzbal, I.; Schmitz, M.F.; Pineda, F.D. Integrating Landscape Analysis and Planning: A Multi-Scale Approach for Oriented Management of Tourist Recreation. Environ. Manag. 2009, 44, 938-951. [CrossRef]

28. Pôças, I.; Cunha, M.; Pereira, L.S. Remote sensing based indicators of changes in a mountain rural landscape of Northeast Portugal. Appl. Geogr. 2011, 31, 871-880. [CrossRef]

29. Lomba, A.; Guerra, D.; Alonso, J.; Honrado, J.P.; Jongman, R.; McCracken, D. Mapping and monitoring High Nature Value farmlands: Challenges in European landscapes. J. Environ. Manag. 2014, 143, 140-150. [CrossRef]

30. Uumaa, E.; Mander, Ü.; Marja, R. Trends in the use of landscape spatial metrics as landscape indicators: A review. Ecol. Indic. 2013, 28, 100-106. [CrossRef]

31. Tortora, A.; Statuto, D.; Picuno, P. Rural landscape planning through spatial modelling and image processing of historical maps. Land Use Policy 2015, 42, 71-82. [CrossRef]

32. CREA. L'agricoltura Italiana Conta. In Proceedings of the CREA Consiglio Per La Ricerca in Agricoltura e L'analisi Dell'economia Agraria, Rome, Italy, 2015. 
33. ISTAT-Istituto Nazionale di Statistica. Rapporto BES 2014: Il Benessere Equo E Sostenibile in Italia; ISTAT: Rome, Italy, 2014.

34. Agnoletti, M. The degradation of traditional landscape in a mountain area of Tuscany during the 19th and 20th centuries: Implications for biodiversity and sustainable management. For. Ecol. Manag. 2007, 249, 5-17. [CrossRef] 